\title{
ANALISIS TOTAL PRODUCTIVE MAINTENANCE (TPM) MENGGUNAKAN OVERALL EQUIPMENT EFFECTIVENESS DI PT. PERKEBUNAN NUSANTARA VI OPHIR
}

\author{
Abdul Latif ${ }^{1)}$, Ratno Purnomo ${ }^{2)}$ \\ Program Studi Teknik Industri Sekolah Tinggi Teknologi Industri (STTIND) Padang \\ Email. abdullatief@sttind.ac.id, ratnopurnomo1215@gmail.com
}

\begin{abstract}
Abstrak: PT. Perkebunan Nusantara VI Ophir Pasaman Barat merupakan salah satu unit usaha yang bergerakak di bidang pengolahan buah kelapa sawit. Pada perusahaan ini masih terdapat kerusakan pada komponen-komponen mesin dan berkurangnya jumlah produksi minyak kelapa sawit, dengan banyaknya kerusakan dan kerugian perusahaan yang bergerak dalam bidang pengolahan, salah satu mesin yang digunakan adalah mesin Screw Press. Mesin yang beroperasi secara terus menerus. Tujuan penelitian untuk mengetahui nilai $O E E$ pada mesin Screw Press, dan setelah mengetahui nilai OEE maka setelah itu dilakukan pembandingan dengan nilai OEE dunia atau standard world class OEE demi meningkatkan performansi mesin. Overal Equipment Effectiveness merupakan metode untuk mengetahui tingkat efektivitas penggunaan suatu mesin atau peralatan. Hasil pengukuran dipengaruhi oleh enam faktor yang dikenal dengan Six Big Losses. Hasil penelitian menunjukan persentasi rata-rata Bulan Januari - Desember 2016 avaibility rate sebesar 97,948\% - 98.837\%, $6.315 \%-8.282 \%$, performance rate $85.42 \%$, rate of quality product $99,15 \%$. Didapatkan nilai OEE pada mesin screw press sebesar $61.742 \%-81.75 \%$
\end{abstract}

Kata kunci: Efektivitas, Mesin Screw Press, Total productive maintenace (TPM), Overall equipment effectiveness (OEE).

Abstract: PT. Perkebunan Nusantara VI Ophir Pasaman Barat is one of the business units engaged in palm oil processing. At this company there is still damage to the engine components and the reduced amount of palm oil production, with a lot of damage and losses of companies engaged in processing, one of the machines used is the Screw Press machine. Machines that operate continuously. The purpose of this study was to determine the value of OEE on a Screw Press machine, and after knowing the value of OEE then after that it was made a comparison with the world OEE value or OEE world-class standard in order to improve machine performance. Overall Equipment Effectiveness is a method to determine the effectiveness of using a machine or equipment. The measurement results are influenced by six factors known as Six Big Losses. The results showed an average percentage of January December 2016 availability rate of $97.948 \%$ - 98.837\%, 6.315\% -8.282\%, performance rate $85.42 \%$, rate of product quality $99.15 \%$. Obtained OEE value on the screw press machine at $61.742 \%-81.75 \%$.

Keywords: Effectiveness, Screw Press, Total productive maintenance (TPM), Overall equipment effectiveness (OEE).

\section{PENDAHULUAN}

PT. Perkebunan Nusantara VI merupakan pabrik kelapa sawit yang bergerak dalam mengolah TBS menjadi minyak kelapa sawit melalui beberapa tahapan dimulai dari stasiun penerimaan bahan baku, perebusan pemipilan, pressan, pemurnian minyak dan pengeringan inti serta stasiun penimbunan. Dalam setiap tahap, perusahaan sangat mengedepankan mutu dan rendemen. 
Pada pengolahan kelapa sawit di pabrik ada beberapa stasiun atau alat yang menjadi titik kehilangan minyak tersebut yaitu:

stasiun perebusan pada proses perebusan TBS (tandan buah segar) losess terjadi pada pembuangan air kondenset sterilizer, stasiun kempa pada proses pemisahan minyak dari daging buah di stasiun pressan atau screw press losess terjadi pada cake/ampas, dan kebocoran-kebocoran pada instalasi alat, selanjutnya yaitu pada stasiun klarifikasi pada proses pemisahan minyak dari air di stasiun klarifikasi, losess minyak pada buangan setiap tangkitangki pengendapan dan buangan pada alat sentrifuge. Namun pada penelitian ini hanya menitik fokuskan pada stasiun kempa atau mesin screw press, pada umumnya pabrik kelapa sawit memiliki pressan yang mempunyai 2 (dua) screw yang digunakan untuk memisahkan minyak kasar dari serat-serat daging buah. Alat ini dilengkapi silinder press yang berlubang-lubang sebanyak kurang lebih 22.000 buah untuk menyaring minyak dan didalamnya terdapat dua buah uliran screw press yang berputar melawan arah. Pressan diatur oleh dua cone yang berada pada ujung pressan, dan dapat digerakkan maju mundur secara hydrolic. Ketika tekanan hydrolic terlalu rendah, hal ini dapat menyebabkan cake basah, losses minyak pada ampas dan biji bertambah.

Permasalahan yang terjadi di bagian produksi seperti kerusakan komponen mesin dan peralan yang sudah lama tidak digunakan, untuk mengatasi hal tersebut, tindakan yang dilakukan adalah mengidentifikasi penyebab masalah dan menemukan usulan perbaikan. Overall Equipment Effectiveness merupakan salah satu metode yang digunakan untuk mengatasi permasalahan dalam kerusakan mesin dan peralatan. Overall Equipment Effectiveness menjadi satu bagian dari TPM (Total Productive Maintenance) atau disebut dengan sistem pemeliharaan. Tiga faktor penting dalam TPM adalah Avaibility, performance, dan quality.
Keberhasilan dari sistem pemeliharaan diukur dari peralatan produksi yang bekerja secara normal.

Penggunaan peralatan dan mesin secara efektif dan efisien dapat menjaga mesin dalam keadaan baik dan menjaga produktivitas serta menghindari kerugian pada perusahaan. Faktor yang menyebabkan kerusakan atau disebut juga dengan enam kerugian adalah breakdown, set-up, adjusment, idling, minor stoppage losses, dan defect losess

Berdasarkan hal tersebut, tujuan penelitian untuk mengetahui dan menentukan efektivitas penggunaan mesin dan peralatan menggunakan metode Overall Equipment effectiveness pada mesin screw press PT. Perkebunan Nusantara VI Pasaman Barat serta membandingkan hasil perhitungan nilai Overall Equipment Effectiveness dengan world standar OEE

\section{METODE PENELITIAN}

Jenis Penelitian adalah deskriptif kuantitatif. Deskriptif kuantitatif merupakan penelitian dengan pengolahan data berupa angka suatu perusahaan atau industri yang nantinya data akan dikumpulkan dan diolah sehingga memberikan informasi yang berguna dengan menggunakan perumusan matematika. Penelitian dilaksanakan di PT. Perkebunan Nusantara VI, Kabupaten Pasaman Barat.

Data penelitian adalah data produksi screw press 2016 dan juga data jam kerja dan breakdown mesin screw press tahun produksi 2016 di PT. Perkebunan Nusantara VI Pasaman Barat. Pengolahan data dilakukan dengan menentukan rasio ketersediaan, performance rate, quality of rate dan overall equipment effectiveness dengan cara mengalikan hasil dari ketiga rasio tersebut, dan langkah terakhir membandingkan dengan nilai OEE standar dunia 


\section{HASIL DAN PEMBAHASAN}

Berikut ini merupakan tabel daripada data produksi mesin screw press tahun 2016 PT. Perkebunan Nusantara VI Unit Usaha OPHIR.

Tabel 1.1

Data Produksi Screw Press 2016

\begin{tabular}{|c|c|c|c|c|}
\hline \multirow{2}{*}{ No } & Bulan & \multicolumn{3}{|c|}{ Total Produksi (kg) } \\
\cline { 3 - 5 } & & $\begin{array}{c}\text { TBS } \\
\text { Digiling } \\
\text { (Kg) }\end{array}$ & $\begin{array}{c}\text { Inti } \\
\text { (Kg) }\end{array}$ & $\begin{array}{c}\text { CP0 } \\
\text { (Kg) }\end{array}$ \\
\hline 1 & Januari & 24.124 .930 & 1.206 .701 & 5.219 .331 \\
\hline 2 & Februari & 23.378 .447 & 1.230 .177 & 5.22 .116 \\
\hline 3 & Maret & 23.466 .750 & 1.257 .714 & 5.886 .165 \\
\hline 4 & April & 27.042 .541 & 1.361 .472 & 6.227 .772 \\
\hline 5 & Mei & 30.026 .580 & 1.367 .611 & 6.367 .121 \\
\hline 6 & Juni & 30.359 .130 & 1.361 .472 & 6.367 .212 \\
\hline 7 & Juli & 22.896 .928 & 1.174 .390 & 5.118 .169 \\
\hline 8 & Agustus & 26.788 .660 & 1.215 .939 & 5.947 .564 \\
\hline 9 & September & 27.197 .260 & 1.223 .887 & 5.852 .545 \\
\hline 10 & Oktober & 25.309 .560 & 1.135 .916 & 5.437 .112 \\
\hline 11 & November & 28.805 .710 & 1.228 .117 & 6.161 .777 \\
\hline 12 & Desember & 28.158 .950 & 1.233 .113 & 5.859 .837 \\
\hline
\end{tabular}

Sumber : PT. PN IV Unit Usaha Ophir.

Tabel 1.2

Data jam kerja dan Break Down mesin Screw Press pada tahun 2016

\begin{tabular}{|c|c|c|c|c|c|}
\hline No & Bulan & $\begin{array}{c}\text { Total } \\
\text { Break } \\
\text { Down } \\
\text { (Jam) }\end{array}$ & $\begin{array}{c}\text { Jumlah } \\
\text { Produksi } \\
\text { (Kg) }\end{array}$ & $\begin{array}{c}\text { Waktu } \\
\text { Pengol } \\
\text { ahan } \\
\text { (Jam) }\end{array}$ & $\begin{array}{c}\text { Load } \\
\text { ing } \\
\text { Time } \\
\text { Jam) }\end{array}$ \\
\hline 1 & Januari & 11.4 & 24.124 .930 & 378 & 390 \\
\hline 2 & Februari & 16 & 23.378 .447 & 380 & 396 \\
\hline 3 & Maret & 18.2 & 23.466 .750 & 368 & 387 \\
\hline 4 & April & 11.92 & 27.042 .541 & 326 & 338 \\
\hline 5 & Mei & 10.51 & 30.026 .580 & 372 & 383 \\
\hline 6 & Juni & 12 & 30.359 .130 & 375 & 387 \\
\hline 7 & Juli & 2.35 & 22.896 .928 & 411 & 413 \\
\hline 8 & Agustus & 4.7 & 26.788 .660 & 381 & 386 \\
\hline 9 & September & 1.96 & 27.197 .260 & 421 & 423 \\
\hline 10 & Oktober & 15.83 & 25.309 .560 & 387 & 403 \\
\hline 11 & November & 3.01 & 28.805 .710 & 394 & 397 \\
\hline 12 & Desember & 5.91 & 28.158 .950 & 338 & 344 \\
\hline
\end{tabular}

Sumber : PT. PN IV Unit Usaha Ophir

Dari tabel di atas dapat dihitung Overall Equipment Effectiveness di PT. Perkebunan Nusantara, Pasaman Barat.
Menentukan efektivitas mesin atau peralatan dengan menggunakan metode OEE pada mesin screw press

\section{Penentuan Availability Ratio}

Perhitungan Availability Ratio dilakukan untuk menentukan besar ketersediaan mesin atau manfaat peralatan yang digunakan dengan memperhitungkan data waktu operai dan waktu loading:

Availability $=\frac{378}{390} \times 100 \%=$

Tabel 4.3

Hasil perhitungan nilai Availabity rate tahun 2016

\begin{tabular}{|c|c|c|c|}
\hline Bulan & $\begin{array}{c}\text { Wktu } \\
\text { Operasi } \\
\text { (Jam) }\end{array}$ & $\begin{array}{c}\text { Loading } \\
\text { Time } \\
\text { (Jam) }\end{array}$ & Ar \% \\
\hline Januari & 378 & 390 & 96.923 \\
\hline Februari & 380 & 396 & 95.959 \\
\hline Maret & 368 & 387 & 95.090 \\
\hline April & 326 & 338 & 96.449 \\
\hline Mei & 372 & 383 & 97.127 \\
\hline Juni & 375 & 387 & 96.899 \\
\hline Juli & 411 & 413 & 99.515 \\
\hline Agustus & 381 & 386 & 98.704 \\
\hline September & 421 & 423 & 99.527 \\
\hline Oktober & 387 & 403 & 96.029 \\
\hline November & 394 & 397 & 99.244 \\
\hline Desember & 338 & 344 & 98.255 \\
\hline \multicolumn{3}{|c|}{ mlah } & 1171.721 \\
\hline
\end{tabular}

\section{Perhitungan Performance Rate}

Perhitungan performance rate digunakan untuk menentukan keefektifan pada saat kegiatan produksi. Perhitungan dilakukan berdasarkan jumlah input, ideal cycletime dan waktu operasi.

Hasil perhitungan nilai Performance rate untuk Bulan Januari - Bulan Desember disajikan pada tabel 4.4

Tabel 4.4.

Perhitungan Performance Rate pada tahun 2016

\begin{tabular}{|l|c|c|c|c|}
\hline \multicolumn{1}{|c|}{ Bulan } & $\begin{array}{c}\text { Jumlah } \\
\text { input }\end{array}$ & $\begin{array}{c}\text { Ideal } \\
\text { Cycle } \\
\text { Time } \\
\text { (Jam/ } \\
\text { Kg) }\end{array}$ & $\begin{array}{c}\text { Loadin } \\
\text { g } \\
\text { Time } \\
\text { (Jam) }\end{array}$ & Pr \% \\
\hline Januari & 24.124 .930 & 1 & 390 & 6,185 \\
\hline Februari & 23.378 .447 & 1 & 396 & 5,903 \\
\hline Maret & 23.466 .750 & 1 & 387 & 6,063 \\
\hline April & 27.042 .541 & 1 & 338 & 8,000 \\
\hline Mei & 30.026 .580 & 1 & 383 & 7,839 \\
\hline Juni & 30.359 .130 & 1 & 387 & 7,844 \\
\hline Juli & 22.896 .928 & 1 & 413 & 5,544 \\
\hline Agustus & 26.788 .660 & 1 & 386 & 6,940 \\
\hline September & 27.197 .260 & 1 & 423 & 6,429 \\
\hline Oktober & 25.309 .560 & 1 & 403 & 6,280 \\
\hline November & 28.805 .710 & 1 & 397 & 7,255 \\
\hline Desember & 28.158 .950 & 1 & 344 & 8,185 \\
\hline Jumlah & & & & 82,467 \\
\hline
\end{tabular}




\section{Penentuan Nilai Rate of Quality}

Perhitungan nilai rate of quality dilakukan untuk menentukan keefektifan produksi berdasarkan kualitas produksi. Perhitungan ini didasarkan pada jumlah input dan jumlah cacat.

$$
\text { Perhitungan Rate of Quality }
$$
tertuang dalam tabel 4.5:

Tabel 4.5

Perhitungan Rate of Quality tahun 2016

\begin{tabular}{|c|c|c|c|c|}
\hline Bulan & $\begin{array}{c}\text { Jumlah } \\
\text { Input }\end{array}$ & $\begin{array}{c}\text { Prod } \\
\mathbf{u k} \\
\mathbf{C a c a} \\
\mathbf{t} \\
\mathbf{K g})\end{array}$ & Hasil (Kg) & Rq \% \\
\hline Januari & 24.124 .930 & 4.366 & 24.196 .271 & 99,687 \\
\hline Februari & 23.378 .447 & 3.456 & 23.537 .887 & 99,307 \\
\hline Maret & 23.466 .750 & 6.519 & 23.602 .563 & 99,396 \\
\hline April & 27.042 .541 & 3.222 & 27.210 .321 & 99,371 \\
\hline Mei & 30.026 .580 & 4.891 & 30.026 .673 & 99,983 \\
\hline Juni & 30.359 .130 & 4.670 & 30.412 .432 & 99,809 \\
\hline Juli & 22.896 .928 & 4.180 & 22.962 .128 & 99,697 \\
\hline Agustus & 26.788 .660 & 3.491 & 26.853 .751 & 99,744 \\
\hline September & 27.197 .260 & 3.850 & 27.275 .761 & 99,698 \\
\hline Oktober & 25.309 .560 & 3.850 & 25.371 .066 & 99,742 \\
\hline November & 28.805 .710 & 3.718 & 28.809 .534 & 99,973 \\
\hline Desember & 28.158 .950 & 3.750 & 28.232 .458 & 99,726 \\
\hline \multicolumn{5}{|c}{ Jumlah } \\
\hline \multicolumn{5}{|c}{} \\
\hline
\end{tabular}

\section{Penentuan Overall Equipment Effectiveness}

Nilai Overall didapatkan dengan mengalikan nilai availability, nilai performance, dan nilai quality rate.

Tabel 4.6

Hasil Perhitungan $\mathrm{OEE}$

\begin{tabular}{|c|c|c|c|c|}
\hline Bulan & AR \% & PR \% & RQ \% & OEE \% \\
\hline Januari & 97,923 & 6,185 & 99,687 & $60.375,80$ \\
\hline Februari & 95,959 & 5,903 & 99,307 & $56.252,05$ \\
\hline Maret & 95,090 & 6,063 & 99,396 & $57.304,84$ \\
\hline April & 96,449 & 8,000 & 99,371 & $76.673,86$ \\
\hline Mei & 97,127 & 7,839 & 99,983 & $76.124,91$ \\
\hline Juni & 96,899 & 7,844 & 99,809 & $75.862,40$ \\
\hline Juli & 99,515 & 5,544 & 99,697 & $55.003,94$ \\
\hline Agustus & 98,704 & 6,940 & 99,744 & $69.017,43$ \\
\hline September & 99,527 & 6,429 & 99,698 & $63.792,67$ \\
\hline Oktober & 96,029 & 6,280 & 99,742 & $60.150,62$ \\
\hline November & 99,244 & 7,255 & 99,973 & $71.982,08$ \\
\hline Desember & 98,255 & 8,185 & 99,726 & $80.201,36$ \\
\hline \multicolumn{5}{|c}{ Rata Rata } \\
\hline
\end{tabular}

\section{Membandingkan nilai Overall Equipment Effectiveness dengan world standard $\mathrm{OEE}$}

Berdasarkan pengolahan data dari mesin screw press menggunakan metode Overall Equipment Effectiveness di PT. Perkebunan Nusantara VI Unit Usaha Ophir Pasaman Barat pada tahun 2016, selama bulan Januari - Desember 2016, hasil perhitungan didapat sebagai berikut:

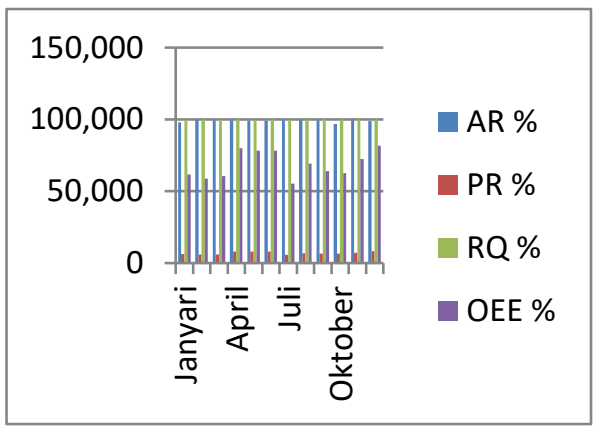

Gambar 4.1. Grafik Nilai OEE

Berdasarkan grafik nilai Overall Equipment Effectiveness, diketahui perhitungan sebagai berikut:

1. Periode Januari - Desember 2016 nilai Overall Equipment Effectiveness antara $60.375 \%$ - $80.201 \%$. Nilai perhitungan Availability Ratio berkisar antara $95.090 \%$ - 99.527\%, performance ratio berkisar antara $5.544 \%-8.185 \%$ dan rate of quality product dengan nilai $99.307 \%-99.9835$.

2. Nilai Overall Equipment Effectiveness tertinggi terdapat pada bulan Desember sebesar $80.0201 \%$. Penyebab tingginya adalah tingkat availability ratio sebesar $98.255 \%$, nilai performance ratio sebesar $8.185 \%$ dan nilai quality product sebesar $99.726 \%$

3. Nilai Overall Equipment Effectiveness terendah terjadi pada bulan Juli sebesar $55.003 \%$. Hal ini disebabkan karena tingkat availability rasio,performance ratio, dan rate of quality rendah

Setelah nilai Overall Equipment Effectiveness diketahui, kemudian untuk mengetahui perbandingan nilai Overall equipment effectiveness dengan world 
standard OEE, berikut tabel 4.7 untuk melihat perbadingan:

\section{Tabel 4.7}

Perbandingan Nilai Perhitungan

Availability, performance \& rate of quality ratio dengan standar world classs

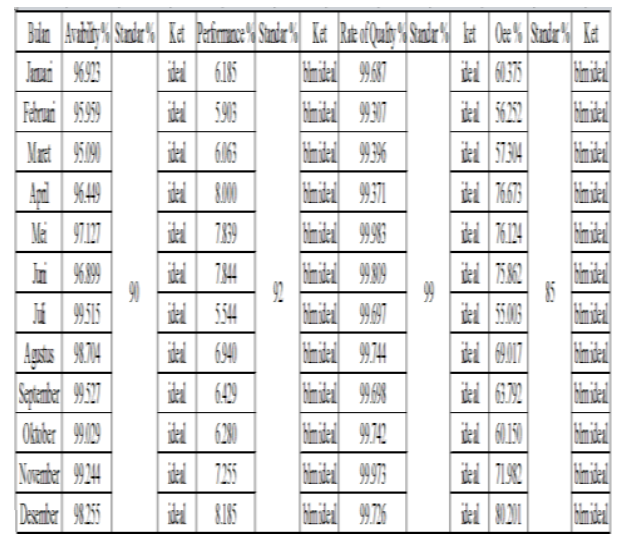

Berdasarkan pembandingan nilai Availability, Performance \& Rate of Quality Ratio terhadap standar World Class dapat diketahui:

1. Berdasarkan hasil tersebut, nilai Availability bulan Januari-Desember sudah menunjukan hasil Ideal. Dari perbandingan nilai availability dengan ketetapan nilai availability ideal yang lebih besar dari 90\%. Dapat disimpulkan bahwa pada mesin screw press sudah mempunyai nilai availability yang baik.

2. Nilai Performance Efficiency menunjukkan belum bisa dikatakan ideal karena Bulan Januari-Desember berada dibawah standar yaitu lebih kecil dari $92 \%$.

3. Nilai rate of quality product sudah ideal pada Bulan Januari - Desember karena dapat di lihat dari nilai Performance Efficiency dibandingkan dengan ketetapan nilai Performance Efficiency yang lebih besar dari 99\% sehingga dapat di katakan bahwa mesin Screw Press sudah mempunyai nilai Screw Press yang baik.

4. Overall Equipment Effectiveness belum Ideal pada bulan Januari-Desember karena masih berada dibawah standar $85 \%$. Hal ini disebabkan karena tidak tercapainya nilai Performance Efficiency

\section{KESIMPULAN}

1. Berdasarkan dari perhitungan pada bab IV besar nilai Overall Equipment Effectiveness rata-rata di PT. Perkebunan Nusantara VI Unit Usaha Opir Pasaman Barat pada mesin Screw Press dari bulan Januari-Desember ialah sebesar 66,895\%. Berdasarkan analisa Overall Equipment Effectiveness sistem perawatan saat ini diterapkan belum baik karena belum sesuai dengan standar yang ditetapkan JIPM (>85\%).

2. Perhitungan nilai $O E E$ yang telah di peroleh tersebut maka dapat dilihat perbandingan nilai OEE yakni, nilai Availability bulan Januari-Desember sudah Ideal. Dari perbandingan nilai Availability dengan ketetapan nilai availability ideal yang lebih besar dari $90 \%$, dapat disimpulkan bahwa Mesin Screw Press sudah mempunyai nilai Availability yang baik. Nilai Performance Efficiency belum dapat dikatakan ideal atau baik karena pada Januari-Desember berada dibawah standar yaitu lebih kecil dari $92 \%$. Nilai rata- rata Rate Of Quality Product bulan Januari - Desember sudah Ideal karena dapat di lihat dari nilai Performance Efficiency dibandingkan dengan ketetapan nilai Performance Efficiency yang lebih besar dari 99\% sehingga dapat di katakan bahwa mesin Screw Press sudah mempunyai nilai Screw Press yang baik. Nilai Overall Equipment Effectiveness belum Ideal hal ini disebabkan pada bulan JanuariDesember nilai $O E E$ nya masih berada dibawah standar 85\%. Hal ini disebabkan karena tidak tercapainya nilai Performance Efficiency. 


\section{DAFTAR PUSTAKA}

Ansori, Nachrul dan mstajid, M.Imron, Sistem Perawatan Mesin Terpadu. Graha Ilmu, Yogyakarta, 2013

Abdul Wahid, Rahmad Agung. Perhitungan Total Produktifitas Maintenance Pada Mesin Bobin dengan Pendekatan Overall Equipment Effectiveness di PT. Xy. Jurnal Nasional. 2016

Afif, Fahmi. Implementasi Total Productive Maintenance sebagai Penunjang Produktivitas dengan Pengukuran Overall Equipment Effectiveness pada Mesin Rotary Kth-8. Jurnal Nasional. 2013

Agustinus, Eko Susetyo. Anaisis Overall Equipment Effectiveness untuk Menentukan Efektifitas Mesin. Jurnal Nasional, 2017

Daryanto. Model pembelajaran inovatif. Gava media. Yogyakarta. 2012.

Erni Krisnaningsih. Usulan Penerapan TPM dalam Rangka Peningkatan Efektifitas Mesin. Jurnal Nasional. 2015

Handoko. Dasar-dasar Manajemen Produksi dan Operasi. Yogyakarta. 2011

J. Revianto. Produktivitas dan manajemen. Ugm press. Yogyakarta. 1985.

Sinungan. Produktivitas apa dan bagaimana. Bumi aksara. Bandung, 2000 . 